\title{
The Influence of Uncertainty Reduction Strategy over Social Network Sites Preference
}

\author{
Sarah Gambo', Bahire Özad² \\ ${ }^{1}$ Eastern Mediterranean University, Faculty of Communication and Media Studies, North Cyprus, \\ 15600095@students.emu.edu.tr \\ 2 Eastern Mediterranean University, Faculty of Communication and Media Studies, North Cyprus, \\ bahire.ozad@emu.edu.tr
}

Received 19 January 2020; received in revised form 27 June 2020; accepted 24 July 2020

\begin{abstract}
Proliferation of social media platforms such as Facebook, Instagram, Twitter, WhatsApp, Snapchat and others among their numerous strengths unfortunately came along with some inconveniences such as uncertainty users face during communication. The aim of this study is to determine the preference of Social Networking Sites for uncertainty reduction by international students and local community. The research adopted quantitative methodology to find out international students' preference of Social Networking Sites with respect to reducing the level of uncertainty. In line with previous research, results of the study indicate a direct relationship between preference of SNSs and low-level of uncertainty. Thus, the results reveal that active, passive and interactive strategies used by the international students play an important role in the degree of uncertainty faced by the local and international students.
\end{abstract}

Keywords: Preference, Social network sites, Uncertainty reduction, Multicultural environment, Gratification 


\section{Introduction}

At the outset of the $21^{\text {st }}$ century, SNSs play a significant role in our lives all over the world. The globe has been completely interconnected due to the vast growth of SNSs, and today, SNSs has become fastest means of communication and social media has become the active tool to communicate in our present society having impact greatly on lives [37]. [3] [8], [9], [22], [60] maintain the use of SNSs such as WhatsApp, Twitter, Facebook; and Instagram have provided an array of means of communication for users all over the world [45]. Also, the interactive and collaborative nature of the means of communication they offer provide numerous benefits to the users [15], [34], [49]. SNSs have shown benefits of supporting interactive, collaboration among users, the proliferation and use of social media increases [1], [50], [51]. Leavey [42] explain that users share their information with others through creating of virtual communities to allow interactivity. Information that is shared with others is created with the help of the tools. studies have shown that the use of some SNSs such as Facebook, Twitter, and others have helped generate the data and information content shareable with the application of web 2.0 aim at creating information needed for global use [13], [25], [32], [59].

Faizi, Afia and Chiheb [17] reveal that over 1 billion users of SNSs are engaged in meaningful usage and this has propelled many developments in this field with interest in how users use the platforms for their needs and gratification [7], [57]. These SNSs developments are thereby influencing users' behaviours based on nationality and usage. For example many countries in the world today consider Facebook as most used platform with Asia $=79.72 \%$, Africa $=72.43 \%$, Europe $=76.3 \%$, Turkey $=60.99 \%$ and United States of America $=45.2 \%$. Also, considering Facebook usage $=69.52 \%$ globally [11]. Other platforms global usage and preference include Pinterest $=13.6 \%$, Twitter $=6.11 \%$, YouTube $=4.38 \%$, Reddit $=3.23 \%$ and Instagram $=2.02 \%$ [2], [11]. This trend occurs due to users' activity and gratification derived from the use of these platforms which now become paramount among students since the usage is based on the dimension in communication in the school environment which is seen as multicultural networking [54]. However, most modes of communication vary from one social network to another and are determined by users' choice of the platform so as to satisfy the need for social interaction [20], [24], [62]. Thus, active users are compelled to voluntarily choose the network suitable for direct communication. This helps to reduce uncertainty based on the extensive uses and gratifications that users interact and satisfy with, unrestricted by time, place or delay when communication is demassified [52] that is the use of SNSs for communicating are affected by uncertainty due to background of users, culture and socio-economic, nationality and differences among local and international students.

Since the 21st century, people have continued adapting to the new way of life through communication and the use of social media cut across different facets of human endeavours in creating and expanding the frontiers of social network activities to improve communication, collaboration, and sharing of content [40], [47]. As stated by Berger and Calabrese [6] that the use of SNSs to maintain unique relationships receives a significant impact on the use of SNSs. Therefore, SNSs perform a vital role in the enactment of social relationships with the users' to reduce uncertainty effects while searching for information on social media platforms have improve the way and manner people interact [61], [41]. This process of reducing uncertainty has helped to improve the predictability of social behaviour, tension and conflicts, social consciousness, loneliness, leisure and entertainment, and creative expression of ones' idea [60]. The key concept of uncertainty shows human inability to understand certain behaviour that is typically presented in an social interaction that makes prevision difficult during constructive discussion [38]. However, the theory of uncertainty reduction typically searches for valuable information on the level of increase or decreases in communicating so as to measure the level of uncertainty [6], [39] and the use of uncertainty reduction in different online contexts is to connect, extend a social cycle and to make known one's personal information on a platform (social presence). This is based on the considerable amount of information both of them transmitted per time, the extensive use SNSs for effective purpose and finding solution to ambiguity and uncertainty [36]. This study typically extends the three uncertainty reduction strategies (URSs) in the context of SNSs and their mode of communicating to identify its influence on low-level of uncertainty of information. The URSs include passive, interactive and active strategies [5], [21] which frequently used to reduce uncertainty among users. The low-level of uncertainty unfolds the initial interaction before engaging with effective communication, based on the assumption that the other person communicates with an unknown or has little knowledge of conservation [6]. The primary function of URSs is to gather information on social media platforms which are overtly or covertly done; aimed at reducing uncertainty either passively, interactively or actively, this means that the URSs can be used to monitor the situation, information gathering of diversity and interactivity [28], [52], [55]. However, as online communication is inevitable and now a global phenomenon [25], the key questions are: which of the uncertainty reduction strategy is best utilized by the students? Can international students or host community identify a means through which they can communicate using SNSs to reduce their uncertainty? Do the international students, and the host community contributes immensely to address the social challenges experienced such loneliness, satisfying their psychological, motivation and social needs [11], [27]. Therefore, the present study tentatively proposes to measure uncertainty reduction strategies and low-level of uncertainty and low-level of uncertainty on the continuous preferred of SNSs usage among the host community and international students.

Previous studies typically show that the use of SNSs serve as a means of connecting international students with home countries, family and friends [19], [14], [23], [35]. Furthermore, it helps to cope psychologically and increased 
their well-being [44]. So the preference use of SNSs among potential users has helped in the continuous use of SNSs as a choice to communicate both within the learning environment and internationally [10], [46] to ensure communication can take place among online users. Therefore, this research is centred on the SNSs usage and preference of sites for uncertainty reduction which involve preference of online users, uncertainty reduction strategies' (passive, active and interactive) to the level of uncertainty and purpose of continuous use of SNSs among the host and international students. The gap in the study is to properly explore the use and preference of SNSs to reduce the level of uncertainty by using uncertainty reduction strategy to examine how social media is used to maintain relative uncertainty among users to continuously use SNSs as a tool to develop the cyberspace.

\section{Research model and Hypotheses}

In this section, the research variables and hypotheses are presented with Figure 1. Showing the research model

\subsection{The influence Uncertainty Reduction Strategies on Low-level of Uncertainty}

The social relationship between uncertainty reduction strategies (URSs) and low-level of uncertainty has been studied by [5], [55]. The effective use of SNSs efficiently is to undoubtedly help progressively reduce moral ambiguity and uncertainty during the mode of effective communication [36]. However, based on the three concepts of URSs which focuses on three factors of uncertainty reduction strategies include active, passive and interactive reduction strategies [6]. The extension of these three factors uncertainty reduction strategies in the context of SNSs and its mode of communicating locally and internationally. This helps in identifying the level of uncertainty of information about host and international students. First, according to Emmers and Canary [16] active strategies represent the process of searching for information about a target without directly known the target and this involves proactive efforts to perceive the targeted person, without confronting the person, for example, by questioning other people about the target person and mostly it includes third-party consent of information acquisition. On the effective use of SNSs, uniquely identifying the specific target is always linked to on the low-level of uncertainty on the use of SNSs primarily seeking necessary information about friends, family or acquaintances. This helps to typically establish a direct relationship between host community and international students' practical use of active strategies on low-level of uncertainty.

Second, passive uncertainty reduction strategies represents a pattern of gathering information about a target person by collecting information in an modest way [16]. An effective relationship in online communication environment such as lurking in chat-rooms or being blind copied on email messages [18]. Passive strategy uses gratification theory of communication to meet users need and to fulfil their motives because information seekers behaviours are different predicator for self-expression and interpersonal communication which require users to be primarily influenced by it and conclude based on the low-level of uncertainty of an individual's actions on SNSs. Third, interactive uncertainty reduction strategies include one uncertainty reduction process that typically involves searching for information in some specific form of direct contact with one another. To reduce uncertainty individuals must be attentive to other behaviours when there is high incentive value that could benefit them through rewards available from another person [5] [18]. The use of interactive strategies and low-level of uncertainty represent strategy to gather information through using self-disclosure, question asking and question/disclosure intimacy [4] to reduce level of uncertainty on SNSs use. Therefore, prior to the previous studies, the following hypotheses are stated as follow:

H1: The use of active uncertainty reduction strategies is positively related to the low-level of uncertainty on SNSs use.

H2: The use of passive uncertainty reduction strategies is positively related to the low-level of uncertainty on SNSS use.

H3: The use of interactive uncertainty reduction strategies is positively related to the low-level of uncertainty on SNSs use.

\subsection{The influence of Preference of Network on Continuous Preferred SNSs usage}

The potential benefits of users preference of the SNSs are acknowledged by preferred level of usage of SNSs. As previous studies show that students social-interaction have been ignited by the relationship between students' preference of network and the ability to continue the use of available SNSs [4], [5], [48], [55]. Burhanna, Seeholzer and Salem [10] stated that SNSs usage in undergraduates is found to be useful with the preference of available social network applications and this creates a social interaction, communication and sharing among the students. Also, [10] result revealed a positive relationship between hosts and international students' preference of social network and continuous preferred of SNSs use. Therefore, the following hypothesis is stated as follow:

H4: Preference of Network is positively related to the continuous preferred of SNSs use. 


\subsection{The influence of Low Level of Uncertainty on Preferred SNSs Usage}

The relationship between low-level of uncertainty and preferred SNSs usage has been proposed and tested in various forms of SNSs research [4] [5], [55], [26]. In addition, Burhanna, Seeholzer and Salem [10] found that interactive strategies have a significant effect on low level of uncertainty which also resulted to user's social attractiveness in term of SNSs use. This mutual relationship supports low level of uncertainty on continuous preferred of SNSs use and when uncertainty is low the SNSs increase, inputs, desire, users feel more comfortable and receptive to use SNSs more. For example among host and international students. Li and Peng [43] show adoption of SNSs is new topic among college students' on their media consumption patterns and the relationship between SNSs use and low-level of uncertainty among college students has become a major topic in social media research without a conclusive results. Therefore, the following hypotheses are stated as follow:

H5: low-level of uncertainty is positively related to the continuous preferred of SNSs use.

\section{Research Methodology}

The conceptual model of this study is shown in Figure 1. The proposed research model consists of four factors three dimension of URSs, preference of network, low level of uncertainty and continuous preferred of SNSs use. The study uses these factors to examine the impact of URSs on low level of uncertainty, and preference of network and low level of uncertainty on continuous preferred of SNSs use among host community and international students.

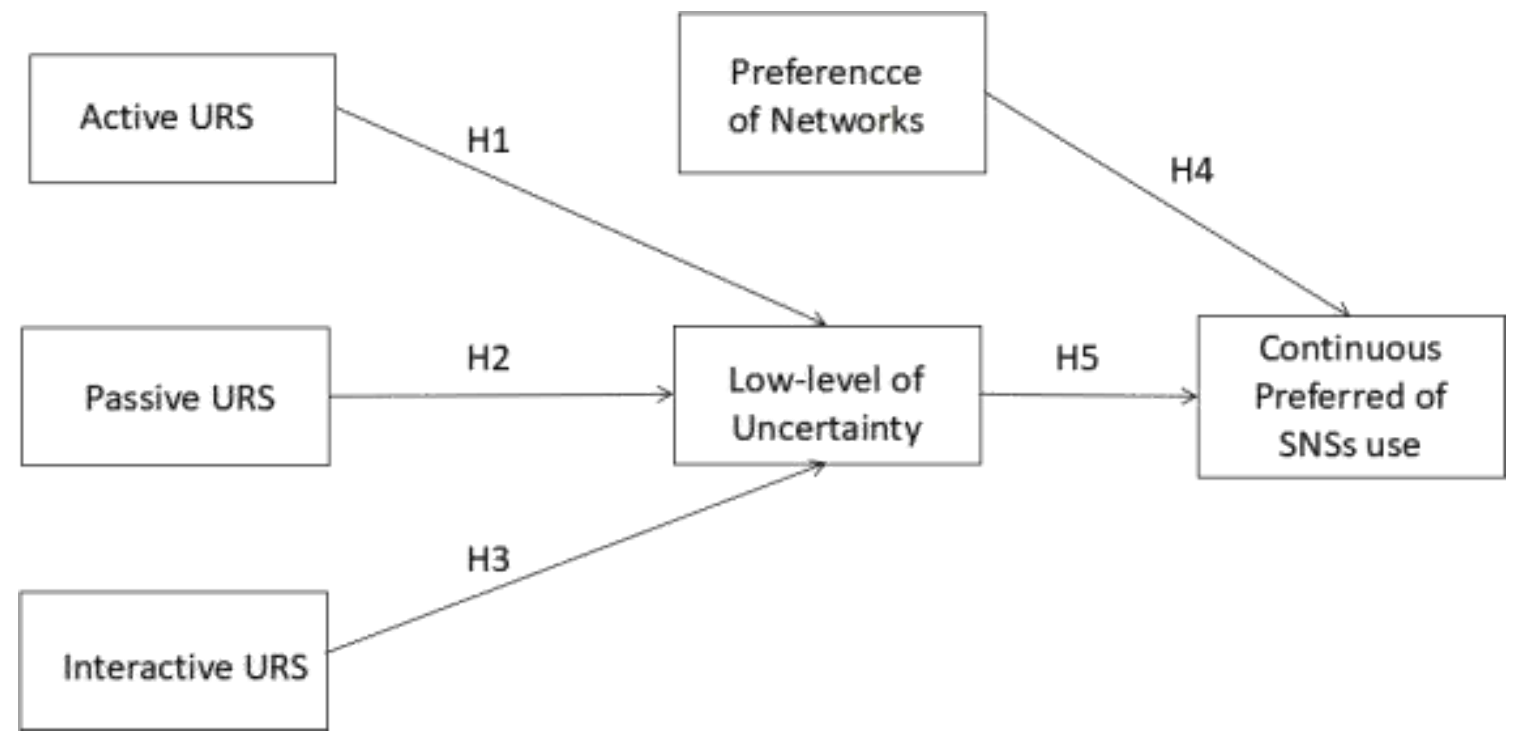

Figure 1: Proposed Research model.

\subsection{Research Instrument}

The aim of this study is to determine relationship between URSs and low level of uncertainty, and preference of network and low level of uncertainty on continuous preferred SNSs usage the host community and international student during communication with different places. This research considers the younger population and their choice of platforms. This study used quantitative study approach. In-house questionnaire was designed by the researchers to collect the data and distributed to the population of the study through WhatsApp platform and the reason for using the social platforms is to collect data through SNSs and ensure that the research is adequately measure the statistical distribution of questionnaire collected from the target population. The study adopted users of preferential of network (Facebook, Twitter Snapchat, Instagram and others - WhatsApp, Drive, DropBox, Skype, Zoom, WeChat based on their popularity that SNSs among target population and the target population of this study are the host community and international students who use the SNSs, experience visiting the SNSs pages as often as possible and subscribe to SNSs presently. All participants were asked to complete a questionnaire based on their demographic information. A total of 500 SNSs users were given the survey questions and 450 respondents completed the survey at $71.1 \%$ of initial respondents 
Table 1: Frequencies of demographic

\begin{tabular}{|l|l|l|l|}
\hline \multicolumn{1}{|c|}{ Levels } & Counts & $\%$ of Total & Cumulative \% \\
\hline Gender & \multicolumn{3}{l|}{} \\
\hline Male & 247 & $54.9 \%$ & $54.9 \%$ \\
\hline Female & 203 & $45.1 \%$ & $100.0 \%$ \\
\hline Age & \multicolumn{2}{l|}{} \\
\hline $16-23$ & 201 & $44.6 \%$ & $44.6 \%$ \\
\hline $24-31$ & 182 & $40.4 \%$ & $40.4 \%$ \\
\hline $32-39$ & 49 & $10.9 \%$ & $10.9 \%$ \\
\hline $40-47$ & 18 & $4.0 \%$ & $100.0 \%$ \\
\hline Qualification & \multicolumn{3}{|l}{} \\
\hline Undergraduate & 257 & $57.1 \%$ & $57.1 \%$ \\
\hline Graduate & 180 & $40.0 \%$ & $97.1 \%$ \\
\hline Ph.D & 13 & $2.9 \%$ & $100.0 \%$ \\
\hline Nationality -Student & \multicolumn{3}{|l}{} \\
\hline International & 360 & $80 \%$ & $80 \%$ \\
\hline Host & 90 & $20 \%$ & $100 \%$ \\
\hline
\end{tabular}

From Table 1, 45.1\% were female and $54.9 \%$ were male. Thus, This results shows sample appeared to be male dominant in gender distribution. Also, The result shows that $57.1 \%$ were undergraduate, $40.0 \%$ were graduate degrees and less than 3\% were Ph.D students that participated in the survey. $44.6 \%$ of respondents were between 16 and 23 years of age, $40.4 \%$ were between 24 and 31 years, $10.9 \%$ of respondents were between 32 and 39 years of age and $4.0 \%$ of respondents were between 40 and 47 years of age. Also, $80 \%$ of the international students participated and $20 \%$ were from the Host community.

From Table 2, the respondents were asked to select one of the SNSs: 1 . which of the platform do you use to communicate with people at home Facebook $(n=70 ; 15.6 \%)$, WhatsApp $(n=218 ; 48.4 \%)$, Instagram $(n=117$; $26.0 \%)$, Twitter $(n=17 ; 3.8 \%)$, Snapchat $(n=25 ; 5.6 \%)$ and Others $(n=3 ; 0.7 \%)$. 2. which platform use to reduce your uncertainty with people at home: Facebook $(n=105 ; 23.3 \%)$, WhatsApp $(n=136 ; 30.2 \%)$, Instagram $(n=116$; $25.8 \%)$, Twitter $(n=36 ; 8.0 \%)$, Snapchat $(n=42 ; 9.3 \%)$ and Others $(n=15 ; 3.3 \%)$. 3. which platform do you think it reduces uncertainty with people in North Cyprus? Facebook $(n=74 ; 16.4 \%)$, WhatsApp $(n=145 ; 32.2 \%)$, Instagram $(n=140 ; 25.8 \%)$, Twitter $(n=35 ; 7.8 \%)$, Snapchat $(n=45 ; 10.0 \%)$ and Others $(n=11 ; 2.4 \%)$. However, these results show that most of the students (Host community or international) prefer WhatsApp as SNSs platform to communicate with people at home, to reduce their uncertainty with people at home most of the students (Host community or international) prefer WhatsApp and most respondents prefer WhatsApp platform prefer in reducing uncertainty with people in North Cyprus. In all cases students prefer WhatsApp as the SNSs platform as a means to communicate, reduce uncertainty with people within host community and internationally.

Table 2: SNSs background Information

\begin{tabular}{|l|l|l|l|}
\hline Items & SNSs & Counts(N) & \% of Total \\
\hline Which of the SNSs platform do you think is better to & & \\
communicate with people at home? & Facebook & 70 & $15.6 \%$ \\
\cline { 2 - 4 } & WhatsApp & 218 & $48.4 \%$ \\
\cline { 2 - 4 } & Instagram & 117 & $26.0 \%$ \\
\cline { 2 - 4 } & Twitter & 17 & $3.8 \%$ \\
\cline { 2 - 4 } & Snapchat & 25 & $5.6 \%$ \\
\cline { 2 - 4 } & Others & 3 & $0.7 \%$ \\
\hline Which SNSs platform do you think it reduces uncertainty with & Facebook & 105 & $23.3 \%$ \\
\cline { 2 - 4 } people at home? Internationally & WhatsApp & 136 & $30.2 \%$ \\
\cline { 2 - 4 } & Instagram & 116 & $25.8 \%$ \\
\cline { 2 - 4 } & Twitter & 36 & $8.0 \%$ \\
\cline { 2 - 4 } & Snapchat & 42 & $9.3 \%$ \\
\cline { 2 - 4 } people in North Cyprus? Host community & Others & 15 & $3.3 \%$ \\
\hline Which SNSs platform do you think it reduces uncertainty with & Facebook & 74 & $16.4 \%$ \\
\cline { 2 - 4 } & WhatsApp & 145 & $32.2 \%$ \\
\cline { 2 - 3 } & Instagram & 140 & $31.1 \%$ \\
\cline { 2 - 3 } & Twitter & 35 & $7.8 \%$ \\
\cline { 2 - 3 } & Snapchat & 45 & $10.0 \%$ \\
\cline { 2 - 3 } & others & 11 & $2.4 \%$ \\
\hline
\end{tabular}




\subsection{Data Collection}

This study developed measurement items for data collection comprises twenty-four items with six constructs of the proposed model and were adopted from the related studies. The items used for this study were modified and wellstructured instrument from existing measures so as to fit into the research context. However, a five-point Likert scales were used to measure the items responses - Low level of uncertainty (LLU), Active level of uncertainty (ALU), Passive level of uncertainty (PLU), preference of Network (PN) and preferred SNSs usage (PSU) ranged from $1=$ strongly disagree to 5 = strongly agree. This study adopted ten items ALU, PLU and LLU from [5]. Three items measuring PN from [55] and CPN were adopted from [30] as shown in Table 3.

Table 3: Measurement items

\begin{tabular}{|c|c|}
\hline CONSTRUCTS & FACTOR LOADINGS \\
\hline \multicolumn{2}{|l|}{ ACTIVE(ALU) } \\
\hline I ask his/ her friends questions about his/her general life. & 0.963 \\
\hline I ask his or her friends about his personal behaviour. & 0.975 \\
\hline I ask his/her questions about his/her spare time. & 0.953 \\
\hline \multicolumn{2}{|l|}{ PASSIVE(PLU) } \\
\hline I read his/her post & 0.959 \\
\hline I read messages on his/her comments & 0.956 \\
\hline I look at their pictures & 0.952 \\
\hline \multicolumn{2}{|l|}{ INTERACTIVE(ILU) } \\
\hline I told him about his/ her posting on social media platforms. & 0.909 \\
\hline I told him about his personal behaviour & 0.893 \\
\hline I told him/her about his/her education or work. & 0.897 \\
\hline I told him/her about his/ her spare time. & 0.972 \\
\hline \multicolumn{2}{|l|}{ PREFERENCE OF NETWORK(PN) } \\
\hline $\begin{array}{l}\text { How long, do you stay on SNSs when communicating with home, host } \\
\text { community and others? }\end{array}$ & 0.968 \\
\hline $\begin{array}{l}\text { On average, do you frequently use SNSs to communicate with students, } \\
\text { home, others }\end{array}$ & 0.967 \\
\hline $\begin{array}{l}\text { How long, do you visit the SNSs for communication purposes with } \\
\text { home, host community and others }\end{array}$ & 0.951 \\
\hline $\begin{array}{l}\text { Do you log-in always on SNSs when communicating with home, host } \\
\text { community and others? }\end{array}$ & 0.951 \\
\hline \multicolumn{2}{|l|}{ LOW -LEVEL OF UNCERTAINTY(LLU) } \\
\hline There is low degree of uncertainty when I use SNSs. & 0.870 \\
\hline $\begin{array}{l}\text { I feel uncertainty associated with the content of some posting on some } \\
\text { platforms. }\end{array}$ & 0.865 \\
\hline $\begin{array}{l}\text { I have confidence that the description of some content on posting using some } \\
\text { platforms are low. }\end{array}$ & 0.855 \\
\hline After using the platform do I like the SNSs when I use it & 0.848 \\
\hline \multicolumn{2}{|l|}{ CONTINUOUS OF PREFERRED SNSs USE (CPN) } \\
\hline $\begin{array}{l}\text { I use the SNSs to search information about people, events, news, and social } \\
\text { activities. }\end{array}$ & 0.892 \\
\hline $\begin{array}{l}\text { I use SNSs help me stay connected with relatives and friends, and help me } \\
\text { stay in contact with others }\end{array}$ & 0.878 \\
\hline I use SNSs to pursue entertaining enjoyable experience in its own right. & 0.878 \\
\hline
\end{tabular}

Measurement items and factor Loadings

\section{Statistical Methods}

Based on the analysis of the survey data, testing the hypotheses and model fit, the study adopted the use of partial least squares (PLS) - ADANCO 2.0.1 software [29] is used to measure variance-based structural equation modelling and tests of model fits, which is commonly use in business and social sciences. ADANCO software can identify model both factors and composites which help in model latent variables of behavioural research. Also, Structural Equation Modeling (SEM) was used to test the Proposed Research model and it comprises a two-stage process. The first step requires a confirmatory factor analysis (CFA) to evaluate the reliability and validity of the measurement model and second step, measuring the model fit to estimate the overall structure model. The CFA and model fit measurement are as follows: 


\subsection{Measurement Model Assessment}

It is essential to measure convergent validity and discriminant validity that is an exploratory analysis, this study examined convergent validity through Cronbach's alpha (a), composite reliability (CR) and average variance extracted (AVE) of latent variables. As shown in Table 4, that is the values of as of the 6 latent variables were $>0.7$ as recommended [12], [53]. Also, the AVE exceeded 0.5 and the CR values exceeded 0.7 as recommended by [20]. Therefore, the convergent validity is accepted.Hence, the study proceeds to measuring discriminant validity.

Table 4: Convergent validity

\begin{tabular}{|l|l|l|l|}
\hline Construct & Average variance extracted (AVE) & CR & Cronbach's alpha $(\alpha)$ \\
\hline CPN & 0.779 & 0.859 & 0.858 \\
\hline PN & 0.930 & 0.977 & 0.975 \\
\hline LLU & 0.739 & 0.889 & 0.883 \\
\hline ALU & 0.928 & 0.966 & 0.961 \\
\hline PLU & 0.914 & 0.957 & 0.953 \\
\hline ILU & 0.810 & 0.902 & 0.884 \\
\hline
\end{tabular}

According to Fomell and Larcker [20] to evaluate the discriminant validity for any given construct, the squared of AVE should exceed the correlations for each of the constructs. Table 5 result shows that the diagonal of the AVE is greater than the level of correlations. So, discriminant validity is accepted.

Table 5: Discriminant validity

\begin{tabular}{|l|l|l|l|l|l|l|}
\hline Construct & PSU & PN & LLU & ALU & PLU & ILU \\
\hline CPN & 0.779 & & & & & \\
\hline PN & 0.284 & 0.930 & & & & \\
\hline LLU & 0.529 & 0.206 & 0.739 & & & \\
\hline ALU & 0.257 & 0.438 & 0.237 & 0.928 & & \\
\hline PLU & 0.172 & 0.181 & 0.183 & 0.179 & 0.914 & \\
\hline ILU & 0.082 & 0.148 & 0.107 & 0.162 & 0.046 & 0.810 \\
\hline Squared correlations; AVE in the diagonal.
\end{tabular}

\subsection{Structural Model Assessment and Hypotheses Testing}

The second step is to estimate the structural model: the standardized path coefficients $(\beta)$, their level of significances ( $p$-value) the coefficient of determinants. The purpose is to measure the model fit of any proposed model and most recent studies in the field of information systems applied the use of structural equation modeling (SEM) for this purpose [9], [33]. This study employed structural equation modeling by using ADANCO to test model fits and determine path analysis. The study applied SEM to measure the impact of user preference of SNSs on continuous preferred of SNSs usage, uncertainty reduction strategies and low level of uncertainty and low level of uncertainty on continuous preferred of SNSs usage. As listed in Table 6, among the factors that influence results is the relationship between URSs and user low-level of uncertainty and this include the relationship between active URS and low-level of the uncertainty of SNSs usage $(\mathrm{H} 1: \beta=0.318, \rho<0.00)$; the relationship between passive URS and low-level of the uncertainty of SNSs usage $(\mathrm{H} 2: \beta=0.263, \rho<0.01)$ and the relationship between interactive URS and low-level of the uncertainty of SNSs usage (H3: $\beta=0.142, \rho<0.01)$, Therefore, URSs do have a positive and significant impact on low-level of the uncertainty of SNSs usage also supports hypothesis 1,2 and 3. Also, the relationship between the preference of networks and preferred SNSs usage $(H 4: \beta=0.160, \rho<0.01)$, this result shows that there is a positive and significant impact between the preference of networks and continuous preferred SNSs usage and the relationship between low level of uncertainty and continuous preferred of SNSs usage (H5: $\beta=0.821, \rho<0.01)$. Therefore, the result shows low-level of uncertainty does have a positive and significant impact on continuous preferred SNSs usage. Therefore, all paths are supported. these results indicate that URSs has a positive and significant impact on low-level of the uncertainty of SNSs usage from the host community and international students, the low-level of the uncertainty of information on SNSs usage from the host community and international students have a positive influence on continuous preferred SNSs usage and both, host and international students' preference of networks on SNSs usage has a positive influence on continuous preferred SNSs usage. 
Table 6: Path coefficients and level of significance

\begin{tabular}{|l|l|l|l|l|}
\hline Effect & Coefficient & t-value & p-value (2-sided) & Accepted/Rejection \\
\hline PN -> CPN & 0.160 & 3.745 & 0.000 & Accepted \\
\hline LLU -> CPN & 0.821 & 19.129 & 0.000 & Accepted \\
\hline ALU -> LLU & 0.318 & 4.959 & 0.000 & Accepted \\
\hline PLU -> LLU & 0.263 & 4.027 & 0.000 & Accepted \\
\hline ILU -> LLU & 0.142 & 2.864 & 0.004 & Accepted \\
\hline
\end{tabular}

Figure 2. presents each standardized path coefficients $(\beta)$ and the coefficient of determinants $\left(R^{2}\right)$. Thus, the study result indicates that the $R^{2}$ for low-level of uncertainty is 0.314 which is proven to be substantial and this jointly accounted for by active, passive and interactive uncertainty reduction strategies at $31.4 \%$ of the total variance of the low level of uncertainty and the $\mathrm{R}^{2}$ for continuous preferred SNSs usage is 0.819 which proven to be significant and this jointly accounted for by low-level of uncertainty and preference of networks at $82 \%$ of the total variance of the continuous preferred SNSs usage. Therefore, the predictive power of low-level of uncertainty and preference of networks has proved to be a strong predictor of continuous preferred SNSs usage for adopting factors of SNSs usage among host and international students (See figure 2).

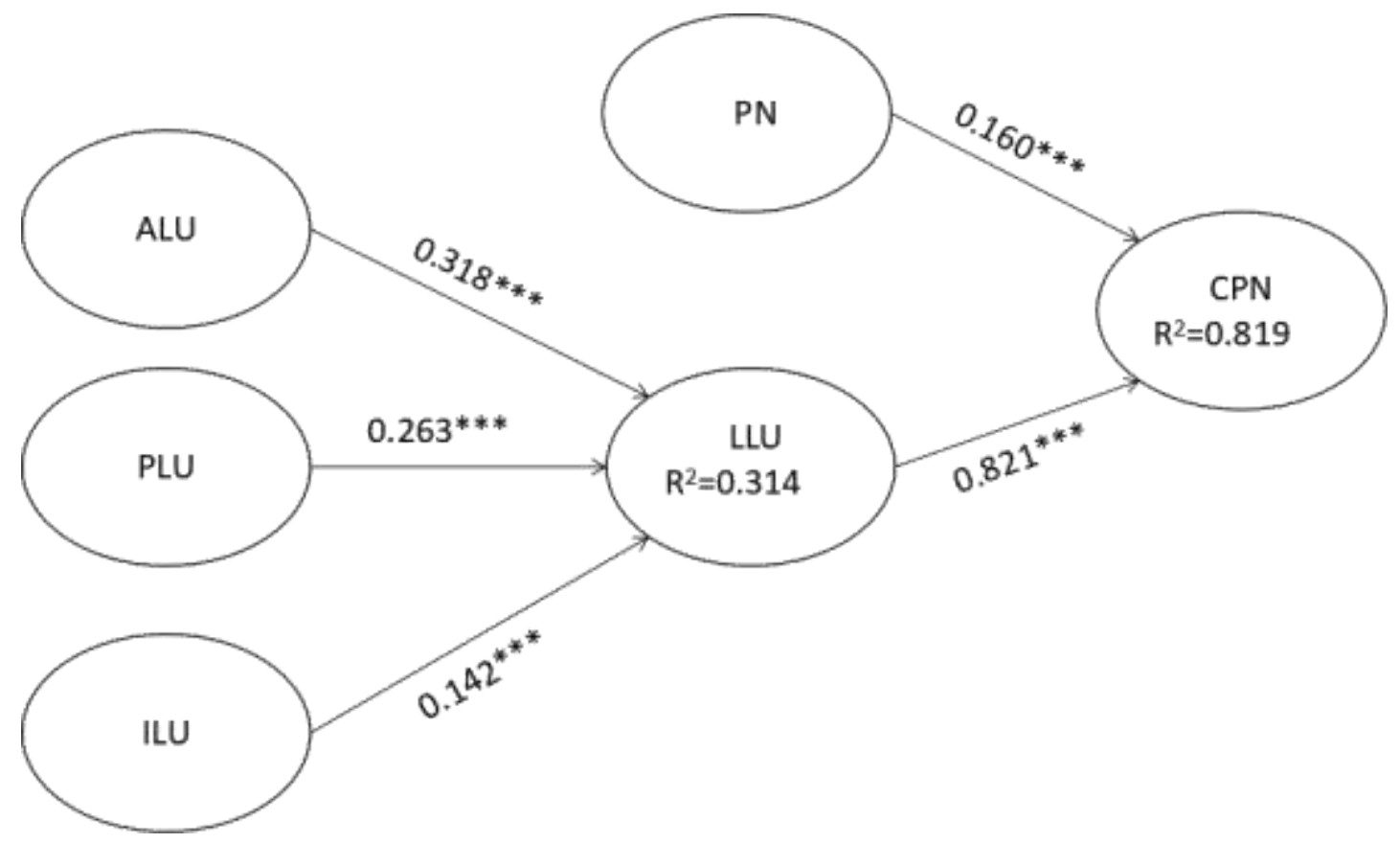

Figure 2: Standardized path coefficients and the coefficient of determinants

\section{Discussions}

This paper explores the influences of user continuous preferred use of SNSs. The present study examines the determinants of URSs to uncover the impact of preference of networks and low-level uncertainty on continuous preferred use of SNSs among the host community and international students. First, the measurement of reliability, convergent and discriminant validity is acceptable based on the exploratory factor analysis. That is, the result has good reliability and both convergent and constructs reliability are acceptable. Also, the study results show that the model is completely fit and acceptable, all the hypotheses are valid, and the relationships among variables are positive with a high significance level. The preliminary result revealed that students prefer to use the newer SNSs which in the results, shows that WhatsApp is highly preferential among other platforms which show that student media behaviours changes based on the unfolding stages of advancement in technology, making the internet interactive to the varieties of advantages over other platforms and feeling of social presence which the platform brings to host and international students.

Second, the study results found that factors of URSs play a significant function in users' low-level uncertainty on SNSs usage among host and international students which is consistent with previous studies on URSs relationship with low-level uncertainty on SNSs usage [18], [39], [55], with regards of the positive influence of URSs on low-level of uncertainty, the result obtained shows that by active, passive and interactive strategies play an important role in the degree of uncertainty about the activities of host and international students. Therefore the study suggests in the 
context of subject matter both URSs and users' low-level uncertainty are an important factor for SNSs usage and to reduce uncertainty, individuals need to be attentive (URSs) to others' behaviors when there is high incentive value that could benefit from another person [18] while communicating with family, friends, improve information seeking and motivation over the use of social networks.

Third, the preference of networks plays an important role in the effectiveness and continuous preferred use of SNSs Therefore, the current study result indicates that the choice of networks helps students to continuous preferred the use of SNSs. Thus, the result of the current study provides a similar result to previous studies [10], [55]. Therefore, the preference of different networks makes students socially attract to SNSs. The choice of online meeting dependent on the availability of information that is meaningful for communicating to take place among the host community and international students making most of them active or continuous preferred use of SNSs [31]. Thus, the relationship between the preference of networks and users show social attraction during information-seeking behaviour and help in continuous preferred use of SNSs among the host community and international students.

Also, the result shows the low-level of uncertainty of information and its relationship with continuous preferred SNSs usage is significant to the SNSs use. Therefore, this finding suggests that students using SNSs are strongly in support of the opportunity it offers to the continuous use by professionals, friends, and family in need of information or other social supportive applications and varieties of social interaction. Interestingly, research findings show that the influence of the low degree of uncertainty and preference of networks among host and international students interfere with several information, activities, and behaviours as most users focus on positive experience, emotional satisfaction with the experience achieved from the information expected value and utility benefits [60]. Hence, the overall result shows that SNSs create and change one's characteristics and ability, interconnectivity and multi-group knowledge sharing and with the inclusion of user motivations to increase continuous preferred use of SNSs.

\section{Research Implications}

This study covers both Theoretical and managerial implication of the study, as it is explained in the work below. The section considers the implications of the URSs and its influence over choice of SNS for continuous usage.

\subsection{Theoretical Implications}

This study introduced the factors of URSs to explain the fundamentals of low-level uncertainty, and the influence of preference of networks and low-level certainty on continuous preferred of SNSs use. This research on URSs, lowlevel uncertainty, preference of networks and continuous preferred of SNSs use within the learning environment serves as a new area in the field of information, communication, technology, and management science. However, these study outcomes contribute towards the body of knowledge by examining the influence of uncertainty reduction strategies and preference of SNSs on continuous preferred of SNSs use among host and international students. Even though, there are many studies on SNSs, URSs and low-level uncertainty. To the best of our knowledge, this study is the first empirical study on the proposed model on the influence of uncertainty reduction strategies and preference of social network sites on continuous preferred of SNSs use and serve as an advantage to humancomputer interaction in the online networking and learning environment.

The significant relationships between active, passive, and interactive reduction strategies, preference of networks, preferred SNS usage, and low level of uncertainty reduction strategy particularly on their influence, perceptions, and behaviours among host and international students. This provides a meaningful demand for improvement on student interactivity, emotional experiences, knowledge sharing, expected value, and utility benefits of SNSs to improve on information and communication. Additionally, the theoretical implications of the study pointed out a new approach to the preference of SNSs for uncertainty reduction among host and international students. The study empirical result reveals that preference of network by the host community and the international students is significantly influenced by means of communication - deviance, anticipation and incentive value while the variables covers: information seeking, similarity, amount of communication, reciprocity, liking, non-verbal affiliate expressiveness and intimacy level of communication content which is represented by continuous preferred of SNSs use. Also, active, passive, and interactive of uncertainty reduction behaviours among host and international students and its influence on the effectiveness of different choice of SNSs. This can also help improve, examine and exploit, these factors of proposed which improve the development and exploitation of more driving factors of SNSs use has indicated that the driving factors influence active, passive, and interactive are directly support low-level of uncertainty on the use of SNSs and indirectly support user-preferred continuous use of SNSs.

Second, the findings show the influence of low-level of uncertainty among student using SNSs on continuous preferred SNSs of use. This relationship offers a great insight into host and international students' effort to gather or submit more information to reduce uncertainty about services and rewards offer by SNSs which lead to continuous preferred SNSs use. Also, the findings extend the application and usability of active, passive and interactive strategies to studies of SNSs among host and international students through URSs as suitable strategies for interactivity, information seeking and sharing and communication. 


\subsection{Managerial Implications}

The empirical studies provide applicable implications. First, SNSs play a valuable role in the learning environment. The positive influence of active, passive, and interactive of uncertainty reduction, preference of networks, preferred of SNSs use, and low-level of uncertainty on continuous preferred of SNSs use in the learning environment. This study shows a new dimension of learning the flow of information within the institution and help communities engage (both host and international students) with the use of SNSs; in term of finding useful information, offers/rewards from the use of SNSs. As such, this study implies a high level of engagement with the use of SNSs to determine the amount of conventional information. Second, the study found that active, passive, and interactive uncertainty reduction strategies are both significantly related to users' low levels of uncertainty, while active uncertainty reduction strategies have a stronger relationship with the low level of uncertainty than others. This is because most host and international students use SNSs to search for information about a target without a direct link to the target and this involves proactive efforts to get to know the target person.

Also, the results provide important implications for educational practitioners, especially managers and practitioners on the significance of URSs, the low-level of uncertainty and preference of network among host and international students' for continuous use of SNSs and the managerial implication on this findings provide relevant information on reducing the uncertainty of SNSs among host and international students. Hence since SNSs have shown to be the current and best means of communication and managers should use the platform to provide students' needs also provide access to information so as to reduce the uncertainty during an interaction. Also, managers should be able to update, measure activities of users' and give feedback on their opinion as inactive use of SNSs can affect student emotions and motivation to communicate locally or internationally. Therefore discouraging students' frequent visits and usage SNS platforms with the preference of networks to determine the immediate response to users' comments, post and likes to fosters interaction and communication among students. Additionally, Practitioners should pay attention to the factors of other factors such as gratifications and hedonic methods to communicate with others and allow students to fully participate in online social interaction [33]. Moreso, preference of networks play a significant role in the preferred SNS usage among users, managers should enthusiastically promote posting and comment makes them feel more engaged in the communication which more likely becomes continuous preferred to use SNS usage among host and international students.

\section{Limitations and Future Research}

The study provides positive and fresh perspectives towards Influence of uncertainty reduction strategies and preference of social network sites on ' preferred of SNSs use and a new direction for future research. 1. The study was designed using a cross-sectional approach can be biased in nature and the sample size might be limited to available host and international students. Therefore, a longitudinal approach to the study might be a more effective method to reflect on trending issues such as the perceptions and behavioural effects on the use of SNSs. The study survey responses indicate that (the platform do you use to reduce your uncertainty with people at home, platform do you use to communicate with people at home?) Almost participants prefer WhatsApp as their preference of SNSs as well as users' high degrees of allegiance to the use. Also, future research should focus on new and trending preference of networks or multiple preferences of networks.

Also, the study on individuals' approach of uncertainty strategies among host and international students could be done using different universities or different field. Furthermore, the influence of uncertainty reduction strategies on the low level of uncertainty should be tested on other areas especially administrative section based on content, functionality, and interactivity to enhance users' motive for SNSs use. Future study should consider specific culture or community to determine different variations on the use of SNSs.

\section{References}

[1] S. Alhabash and M. Ma, A tale of four platforms: Motivations and uses of Facebook, Twitter, Instagram, and Snapchat among college students? Social Media + Society, vol. 3, no. 1, pp 1-13, 2017.

[2] S. I. Alsanie, Social media (Facebook, Twitter, WhatsApp) Used, and it's relationship with the university students contact with their families in Saudi Arabia, Universal Journal of Psychology, vol. 3, no. 3, pp. 69-72. 2015.

[3] L. Al-Sharqi, K. Hashim and I. Kutbi, Perceptions of social media impact on students' social behavior: A comparison between arts and science students, International Journal of Education and Social Science, vol. 2, no. 4, pp. 122-131, 2015

[4] M. L. Antheunis, A. P. Schouten, P. M. Valkenburg, and J. Peter, Interactive uncertainty reduction strategies and verbal affection in computer-mediated communication, Communication Research, vol. 39 no. 6, pp. 757780, 2012.

[5] M. L. Autheunis, P. M. Valkenburg and J. Peter, Getting acquainted through social network sites: Testing a model of online uncertainty reduction and social attraction, Computers in Human Behavior, vol. 26, pp. 100-109, 2010. 
[6] C. R. Berger and R. J. Calabrese, Some exploration in initial Interaction and beyond: Towards a developmental theory of interpersonal communication, Human Communication and Research, vol. 1, no. 2, pp. 99-112, 1975.

[7] H. Binsahl, S. Chang and R. Bosua, Identity and belonging: Saudi female international students and their use of social networking sites, Crossings: Journal of Migration \& Culture, vol. 6, no. 1, pp. 81-102, 2015.

[8] D. M. Boyd and N. D. Ellison, Social network sites: Definition, history, and scholarship, Journal of ComputerMediated Communication, vol. 13, no. 1, p. 11, 2007.

[9] A. Bozkurt, A. Karadeniz and S. Koçdar, Social networking sites as communication, interaction, and learning environments: Perceptions and preferences of distance education students, Journal of Learning for Development-JL4D, vol. 4, no. 3, pp. 348-365, 2017.

[10] K. J. Burhanna, J. Seeholzer and Jr, J. Salem, No natives here: A focus group study of student perceptions of Web 2.0 and the academic library, The Journal of Academic Librarianship, vol. 35, no. 6, pp. 523-532, 2009.

[11] L. Chen and L. K. Hanasono, The effect of acculturation on Chinese international students usage of Facebook and Renren, China Media Reseach, vol. 12, no. 1, pp. 46-60, 2016.

[12] W. W. Chin, How to write up and report PLS analyses, in Handbook of Partial Least Squares. Berlin: Springer, Heidelberg, 2010, pp. 655-690.

[13] K. C. Chinthakayala, C. Zhao, J. Kong, and K. Zhang, A comparative study of three social networking websites, World Wide Web, vol. 17 no. 6, pp. 1233-1259, 2014

[14] L. J. Cohen, The Implications of Induction. London, Methuen: Routledge, 2019.

[15] B. Das and J. S. Sahoo, Social networking sites-a critical analysis of its impact on personal and social life, International Journal of Business and Social Science, vol. 2, no. 14, pp. 222-228, 2011.

[16] T. M. Emmers and D. D. Canary, The effect of uncertainty reducing strategies on young couples' relational repair and intimacy, Communication Quarterly, vol. 44, pp. 166-182, 1996

[17] R. Faizi, A. El Afia and R. Chiheb, Exploring the potential benefits of using social media in education, International Journal of Engineering Pedagogy (iJEP), vol. 3, no. 4, pp. 50-53, 2013.

[18] A. J. Flanagin, Commercial markets as communication markets: Uncertainty reduction through mediated information exchange in online auctions, New Media \& Society, vol. 9, no. 3, pp. 401-423, 2007.

[19] E. Forbush and B. Foucault-Welles, Social media use and adaptation among Chinese students beginning to study in the United States, International Journal of Intercultural Relations, vol. 50, pp. 1-12, 2016.

[20] C. Fornell and D. F. Larcker, Evaluating structural equation models with unobservable variables and measurement error, Journal of marketing research, vol. 18, no. 1, pp. 39-50, 1981.

[21] J. Fox and C. Anderegg, Romantic relationship stages and social networking sites: Uncertainty reduction strategies and perceived relational norms on Facebook. Cyberpsychology, Behavior, and Social Networking, vol. 17 no. 11, pp. 685-691, 2014.

[22] M. Garcia-domingo, M. Aranda and V. M. Fuentes, Facebook use in university students: Exposure and reinforcement search, Procedia-Social and Behavioral Sciences, vol. 237, pp. 249-254, 2017.

[23] GradesFixer. (June, 2019) Facebook and the use of uncertainty reduction theory. Gradesfixer. [Online]. Available: https://gradesfixer.com/free-essay-examples/facebook-and-the-use-of-uncertainty-reduction-theory/

[24] D. N. Greenwood, Fame, Facebook, and Twitter: How attitudes about fame predict, Psychology of Popular Media Culture, vol. 2, no. 4, pp. 222-236, 2013.

[25] T. Greitemeyer, Facebook and people's state self-esteem: The impact of the number of other users' Facebook friends, Computers in Human Behavior, vol. 59, pp. 182-186, 2016.

[26] R. Gu, L.-B. Oh and K.Wang, Multi-homing on SNSs: The role of optimum stimulation level and perceived complementarity in need gratification, Information \& Management, vol. 53, no. 6, pp. 752-766, 2016

[27] C. Gwena, W.T. Chinyamurindi and C. Marange, Motives influencing Facebook usage as a social networking site: An empirical study using international students, Acta Commercii, vol.18, no. 1, pp. 1-11. 2018.

[28] L. Hendricks, Equipment investment and growth in developing countries, Journal of Development Economics, vol. 61, no. 2, pp. 335-364, 2000.

[29] J. Henseler. (2017) Adanco 2.0. 1-User manual. Kleve: Composite Modeling GmbH \& Co. [Online]. Available: https://research.utwente.nl/en/publications/adanco-201-user-manual

[30] T. Hu and P. I. N. G. Zhang, Social media usage as a formative construct: Conceptualization, validation, and implication, Journal of Information Technology Management, vol. 27, no. 4, pp.151-168, 2016.

[31] D. J. Hughes, M. Rowe, M. Batey and A. Lee, A tale of two sites: Twitter vs. Facebook and the personality predictors of social media usage, Computers in Human Behavior, vol. 28, no. 2, pp. 561-569, 2012.

[32] Jgramlich. (June, 2019) 10 facts about Americans and Facebook. Pew Research Center. [Online]. Available: https://pewrsr.ch/2LK6uno

[33] N. I. Jaafar, B. Darmawan and M. Y. M. Ariffin, Social networking site adoption in Malaysia and Indonesia, Journal Komunikasi: Malaysian Journal of Communication, vol. 34, no. 1, pp. 115-134, 2018.

[34] W. C. Jacobsen and R. Forste, The wired generation: Academic and social outcomes of electronic media use among university students. Cyberpsychology, Behavior and Social Networking, vol. 14, no. 5, pp. 275-280, 2011

[35] N. I. Kalia, N. Ben Dahmane Mouelhi, S. Tebessi Hachana, F. Malek, and M. Dahmen, Using social networking sites: A qualitative cross-cultural comparison, Communications in Computer and Information Science, vol. 985, no. 22 , pp. $269-285,2019$.

[36] A. M. Kaplan and M. Haenlein, Users of the world, unite! The challenges and opportunities of Social Media, Business Horizons, vol. 53, no. 1, pp. 59-68, 2010.

[37] D. H. Kim, N. K. Seely and J. H Jung, Do you prefer, Pinterest or Instagram? The role of image-sharing SNSs and self-monitoring in enhancing ad effectiveness, Computers in Human Behavior, vol. 70, pp. 535-543. 2017. 
[38] L. K. Knobloch and L. E., Miller, Uncertainty is an intrinsic part of forming relationships (Berger \& Calabrese, 1975; Sunna, in Handbook of relationship initiation. New York: Psychology Press, 2018.

[39] K. W. Kramer, Motivation to reduce uncertainty: A reconceptualization of uncertainty reduction theory, Management Communication Quarterly, vol. 13, no. 2, pp. 305-316, 1999.

[40] S. J. Kwon, E. Park and K. J. Kim, What drives successful social networking services? A comparative analysis of user acceptance of Facebook and Twitter, The Social Science Journal, vol. 51, no. 4, pp. 534-544, 2014.

[41] V. E. Lee, J. B. Smith and M. Cioci, Teachers and principals: Gender-related perceptions of leadership and power in secondary schools, Educational Evaluation and Policy Analysis, vol.15, no. 2, pp.153-180, 1993

[42] J. Leavey, Social media and public policy: What is the evidence, Plough Place, London, Alliance for Useful Evidence report. 2013.

[43] L. Li and W. Peng, Transitioning through social media: International students' SNSs use, perceived social support, and acculturative stress, Computers in Human Behavior, vol. 98, pp. 69-79, 2019.

[44] S. S. Lim and B. Pham, If you are a foreigner in a foreign country, you stick together: Technologically mediated communication and acculturation of migrant students, New Media \& Society, vol. 18, no. 10, pp 2171-2188, 2016.

[45] S. Luna and M. J. Pennock, Social media applications and emergency management: A literature review and research agenda, International journal of disaster risk reduction, vol. 28, pp. 565-577, 2018.

[46] J. L. Ortega, Disciplinary differences in the use of academic social networking sites, Online Information Review, vol. 39, no. 4, pp. 520-536, 2015.

[47] B. E. Özad and G. Uygarer, Attachment needs and social networking sites, Social Behavior and Personality: An International Journal, vol. 42, no.1, pp. 43-52, 2014

[48] E. L. Pelling and K. M. White, The theory of planned behavior applied to young people's use of social networking web sites, CyberPsychology \& Behavior, vol. 12, no. 6, pp. 755-759, 2009.

[49] N. Petrocchi, A. Asnaani, A. P. Martinez, A. Nadkarni, and S. G. Hofmann, Differences between people who use only Facebook and those who use Facebook plus Twitter, International Journal of Human-Computer Interaction, vol. 31, no. 2, pp. 157-165, 2015.

[50] J. Phua, S. V. Jin and J. J. Kim, Uses and gratifications of social networking sites for bridging and bonding social capital: A comparison of Facebook, Twitter, Instagram and Snapchat, Computers in Human Behavior, vol. 72, pp. 115-122, 2017

[51] S. Pittman and B. Reich, Social media and loneliness: Why an Instagram Picture may be worth more than a thousand Twitter words, Computer in Human Behavior, vol. 62, pp. 155-167, 2016.

[52] T. E. Ruggiero, Uses and gratifications theory in the 21 st century, Mass communication \& society, vol. 3, no. 1, pp. 3-37, 2000.

[53] H. M. Sabi, F. M. E. Uzoka, K. Langmia, and F. N. Njeh, Conceptualizing a model for adoption of cloud computing in education, International Journal of Information Management, vol. 36, no. 2, pp. 183-191, 2016.

[54] H. Seo, R. W. Harn, H. Ebrahim, and J. Aldana, International students' social media use and social adjustment, First Monday, vol. 21, no. 11, 2016.

[55] S. I. Shin, K. Y. Lee and S. B Yang, How do uncertainty reduction strategies influence social networking site fan page visiting? Examining the role of uncertainty reduction strategies, loyalty and satisfaction in continuous visiting behavior, Telematics and Informatics, vol. 34, no. 5, pp 449-462, 2017.

[56] Statcounter Globalstat. (June, 2019) Social media stats worldwide. Statcounter Global Stats. [Online]. Available: http://www.gs.statcounter.com/social-med.

[57] E. Stoycheff, J. Liu, K. A, Wibowo, and D. P. Nanni, What have we learned about social media by studying Facebook? A decade in review, New Media \& Society, vol. 19, no. 6, pp. 968-980, 2017.

[58] A. Susilo, Exploring Facebook and WhatsApp as supporting social network applications for English learning in higher education, vol. 1, no. 2, pp 10-24, 2014

[59] S. T. Tong, B. Van Der Heide, L. Langwell, and J. B. Walther, Too much of a good thing? The relationship between number of friends and interpersonal impressions on Facebook, Journal of Computer-Mediated Communication, vol. 13, pp. 531-549, 2008.

[60] H. Waheed, M. Anjum, M. Rehman, and A Khawaja, Investigation of user behavior on social networking sites, PloS one, vol. 12, No. 3, pp. 1-19, 2017.

[61] S. S. Wang and S. J. Hsu, Not so angry birds: Psychological benefits of mobile games, Pacific Asia Journal of the Association for Information Systems, vol. 8, no. 1, 2016.

[62] K. Zafiropoulos, V. Vrana and K. Antoniadis, Use of twitter and Facebook by top European museums, Journal of Tourism, vol. 1, no. 1, pp. 16-24, 2015. 